\title{
¿TRADUCCIÓN O ADAPTACIÓN? FÓRMULAS PARA LA CREACIÓN DE CUÑAS Y SPOTS EN UNA CAMPAÑA PUBLICITARIA
}

\author{
Dolors Bernadas-Suñé1: Universitat Autònoma de Barcelona. España \\ Dolors.Bernadas@uab.cat
}

Núria Arcos- Foix: Universitat Autònoma de Barcelona. España Nuria.Arcos@uab.cat

\section{RESUMEN}

Los planteamientos teóricos de los manuales de radio y de televisión abordan y elogian la especificidad y la riqueza de los lenguajes de uno y otro medio, así como sus posibilidades para la creación de mensajes persuasivos. Pese a ello, en la práctica, el trasvase creativo se intuye cualitativa y cuantitativamente desequilibrado, y cuando uno se enfrenta al estudio de la publicidad radiofónica, a menudo tropieza con afirmaciones vox populi acerca de su falta de creatividad, su escasa explotación del lenguaje sonoro e, incluso, su dependencia respecto a la publicidad televisiva. Partiendo de los conceptos de traducción y adaptación -y en el marco de una investigación comparativa de los mensajes publicitarios en radio y televisión que nace para estudiar en profundidad dicha intuición y descubrir, en definitiva, cómo se aprovechan los diferentes elementos de los lenguajes televisivo y radiofónico en la publicidad actual-, el presente artículo describe los diferentes tipos de relación que se pueden establecer entre cuñas y spots de una misma campaña, en función del grado de similitud o fidelidad entre piezas.

PALABRAS CLAVE: Campaña publicitaria - Publicidad radiofónica - Publicidad televisiva - Traducción - Adaptación

\footnotetext{
${ }^{1}$ Autor correspondiente:

Dolors Bernadas-Suñé: Profesora del Departamento de Publicidad, Relaciones Públicas y Comunicación Audiovisual. Universitat Autònoma de Barcelona (UAB). Barcelona (España).
} 


\title{
TRANSLATION OR ADAPTATION? WAYS OF CREATING RADIO AND TV SPOTS FOR AN ADVERTISING CAMPAIGN
}

\begin{abstract}
Even though radio and television handbooks praise the specific nature and value of both their languages, as well as their means for the construction of persuasive messages, in practice, the creative transfer between them is felt qualitatively and quantitatively unbalanced. Thus, when facing the study of radio advertising one often comes across vox populi statements about its lack of creativity, its poor use of sound language and, even, its dependence on TV advertising. Taking the concepts of translation and adaptation as a starting point, and within the framework of a comparative research about radio and TV spots which aims to analyse the problem in depth in order to find out how the different elements of radio and TV languages are used in today's advertising, this article describes different kinds of connections that can be found between radio and TV spots of the same advertising campaign, according to their resemblance or fidelity.
\end{abstract}

KEY WORDS: Advertising campaign - Radio advertising - Television advertising Translation - Adaptation

\section{INTRODUCCIÓN}

Cuando una agencia de publicidad se enfrenta al reto de crear una campaña, debe tomar una serie de decisiones estratégicas destinadas a garantizar su eficacia, tanto publicitaria como comunicativa. Probablemente, una de las etapas más importantes de este proceso es la definición de la estrategia creativa, la primera fase de la cual culmina con el hallazgo de un concepto creativo.

Esta idea, que responde al contenido básico del anuncio, debe "expresar, de la mejor manera posible para el destinatario de la comunicación, la promesa seleccionada por la estrategia a través de imágenes, palabras y sonido" (Hernández, 1999, p. 159), por lo que se hace necesario adecuarla a los diferentes medios en los que se difundirá la campaña. Gran parte de la eficacia de ésta derivará del hecho de que sus anuncios se construyan en función a las especificidades del soporte para el que han sido creados, tanto a nivel expresivo como de consumo. 
En el caso de la televisión, por ejemplo, habrá que tener en cuenta que su lenguaje formado por imágenes fijas y en movimiento, voz o palabras locutadas, efectos sonoros, música y silencio, así como signos, palabras y otros elementos sobreimpresos, permite enseñar el producto y ejemplificar cómo se utiliza, mediante acciones y personajes concretos situados en espacios determinados, que serán percibidos de la misma forma por todos los telespectadores. También, que su consumo suele ser en el hogar y en compañía, con una penetración del $88,4 \%^{2}$; que su discurso es fugaz, puesto que se desarrolla en el tiempo, en un fluir imparable (a menos que se grabe la emisión), y que, sobre todo durante la publicidad, persiste el zapping.

La radio, en cambio, se caracteriza por un consumo individual y un grado de penetración del $57,7 \%$, por su capacidad de segmentación, por su accesibilidad y su movilidad (se puede oír desde casi cualquier lugar y a cualquier hora), y por su fugacidad (aunque hoy en día el podcasting ya permite parar, rebobinar, avanzar o repetir los mensajes radiofónicos).

Su lenguaje, basado en el sonido (la voz o la palabra, los efectos sonoros, la música y el silencio), no permite ver, sino únicamente imaginar el producto y sus modos de uso, así como los personajes y espacios, que pueden ser diferentes para cada oyente, en función de lo que le dicte su propia experiencia e imaginación.

Así, la diferencia más importante entre los medios televisivo y radiofónico es que mientras el primero trabaja con estímulos visuales y sonoros, el segundo es esencialmente auditivo, aunque "cuando el mensaje está adaptado al medio y elaborado según sus características, es capaz de suscitar una cascada de imágenes visuales en la mente de la audiencia" (Rodero, 2008, p. 2).

Sin embargo, dentro del sector, la radio es considerada un medio publicitario menor que "sólo se usa como base con algunos productos vetados en ciertos medios o cuando el presupuesto de pequeños y medios anunciantes no les permite pagar las tarifas impuestas en los soportes televisivos" (Barbeito \& Vázquez, 1999, p. 208) y que "sigue apostando por fórmulas tradicionales y parece continuar anclado en un papel complementario y de refuerzo de las campañas en relación con otros medios como la televisión o la prensa". (Perona, 2007, p. 219) 
La constante crítica a la publicidad radiofónica de nuestro país y, más concretamente, a su dependencia respecto a los spots televisivos -manifestada tanto por profesionales como por académicos (entre otros, García, 1998; Hernández, 1999; Huertas y Perona, 1999; o Barbeito y Fajula, 2005)-, nos llevó a plantear un estudio comparativo de la publicidad en radio y televisión que, al amparo de Publiradio ${ }^{3}$, pretende analizar en profundidad dicha relación con el fin de descubrir, en última instancia, cómo se aprovechan (o se malbaratan) las posibilidades expresivas de los lenguajes radiofónico y televisivo en la publicidad actual.

\section{METODOLOGÍA}

El presente artículo expone una categorización, resultado de la fase previa del mencionado estudio ${ }^{4}$, de los diferentes tipos de relación posibles entre cuñas y spots de una misma campaña publicitaria en función del grado de fidelidad o similitud de las piezas.

El conocimiento de dichas fórmulas será esencial, en el futuro de esta investigación, para guiar el proceso de comparación de los anuncios radiofónicos y televisivos, determinar en qué medida la sensación de trasvase creativo directo entre televisión y radio es real o sólo un mito, y, en última instancia, establecer parámetros de calidad en el uso de los diferentes recursos sonoros y audiovisuales, para la creación de una ico-sono-esfera ${ }^{5}$ que se enriquece con el buen uso de los diversos elementos compartidos y que se empobrece cuando uno de los medios depende del otro.

\section{ANÁLISIS Y DISCUSIÓN}

\subsection{De la idea creativa a los mensajes publicitarios para radio y televisión: ¿Traducción $o$ adaptación entre medios?}

En el ámbito académico, el tema de la plasmación del concepto creativo en los diferentes medios ha quedado relegado a los manuales de creatividad publicitaria, en los que se exponen las características de la radio y la televisión -entre otros soportes-, y se elogian la especificidad y la riqueza de sus lenguajes, así como sus posibilidades

\footnotetext{
${ }^{3}$ Publiradio, Grup de Recerca en Publicitat i Comunicació Radiofónica (SGR-2009-0454) es un grupo de investigación adscrito al Departamento de Publicidad, Relaciones Públicas y Comunicación Audiovisual de la Universitat Autònoma de Barcelona. Tiene un especial interés en el análisis de los formatos publicitarios que se utilizan en la radio actual, así como por conocer el grado real de explotación de los componentes del lenguaje radiofónico, con el fin de proponer nuevos recursos comunicativos y creativos. Para más información se puede consultar su web:
} 
en cuanto a la creación de mensajes persuasivos. Sin embargo, raramente se analizan spots y cuñas de una misma campaña de forma paralela.

La comparación de anuncios de este tipo se ha abordado, principalmente, en términos de efectividad, más que de realización o de creación en cada uno de los lenguajes correspondientes. Es el caso de Edell y Keller (1989) quienes intentaron determinar cómo la coordinación de la campaña radiofónica y televisiva afectaba al procesamiento cognitivo de los anuncios por parte de la audiencia, centrándose en los radio replay, cuñas que son el audio del spot, como grado máximo de coordinación.

Donde sí se ha procedido al análisis comparativo de piezas de una misma campaña, ha sido en el terreno de la publicidad internacional, pero ya no en relación con los diferentes medios utilizados, sino en cuanto a la forma en que los mensajes se modifican, o no, según el país de emisión. En este sentido, el trasvase de las campañas de un país a otro se puede producir por diferentes vías "ya sea de manera idéntica (estandarizada), a través de la traducción, a través de otras formas de adaptación o por medio de creaciones ex novo" (Corbacho, 2010, p. 183-184).

En este ámbito, pero también en otros -por ejemplo, el cine-, cuando se habla de "traducción audiovisual" se atiende básicamente al cambio de idioma de la pieza, cosa que incide en la capacidad expresiva del texto audiovisual, incluyendo la redacción, la reformulación, el doblaje o el subtitulado, aceptando la existencia de un texto original (texto origen) que da pie a uno de traducido (texto meta).

Sin embargo, está ampliamente aceptado que no se traducen significados, sino mensajes, por lo que, en el proceso de traducción el texto se contempla en toda su integridad. Así lo expresa Chaume cuando dice que "la traducción audiovisual es una modalidad de traducción que incluye los procesos de transferencia interlingüística $e$ intercultural de aquellos textos que transmiten, como minimo, información acústica e información visual simultáneamente" (Chaume, 2003, p. 15).

Aunque esta definición aparta, aparentemente, a la radio por no poseer una información visual directa, cabe considerar que, a través de los elementos del lenguaje radiofónico, es posible la creación de imágenes mentales y, por lo tanto, se puede atribuir a la radio la calidad de medio mecánico con capacidad de traducción a otros medios ${ }^{6}$, o viceversa.

La transcodificación (Rifkin, 1994) ${ }^{7}$ de mensajes de un medio a otro, a pesar de no haber sido analizada específicamente en el caso de campañas publicitarias en distintos medios, sí ha sido ampliamente estudiada en otras disciplinas, como, por 
ejemplo, en la de la adaptación cinematográfica de obras literarias. En estos estudios, hay cierta tendencia a distinguir entre dos tipos de transcodificación, en función del grado de fidelidad entre la obra de origen y la meta: la traducción y la adaptación.

La primera se da cuando la obra meta es similar a la de origen (mismos personajes, mismas acciones, misma ideología, etc., aunque pueda darse cierta pérdida o ganancia de información, la cual es inevitable en cualquier cambio de lenguaje). La segunda, se produce cuando la obra secundaria se aleja de la primaria, modificando a los personajes, las acciones, el tiempo o el espacio, y llegando a generar, en algunos casos, diferentes significados. Aún así, muchos autores utilizan únicamente el término "adaptación" como sinónimo de transcodificación, por lo que dentro de un mismo concepto se unifican un gran rango de grados de parecido posibles entre dos obras.

Aunque sea imposible conocer con seguridad qué anuncio de la campaña (el radiofónico o el televisivo) fue creado primero sin tener acceso a información interna de las agencias, los conceptos de traducción y adaptación son interesantes en el sentido que aportan de una relación de mayor o menor similitud entre dos mensajes vinculados por una misma idea base. Sin embargo, teniendo en cuenta que no son conceptos estancos, sino que más bien responden a los dos extremos de una escala en la que las posiciones intermedias varían mucho, parece fundamental buscar una categorización distinta (o al menos ampliada) para analizar cómo se ha llevado a cabo la plasmación del concepto creativo en cada medio, en función de la fidelidad entre cuñas y spots de una misma campaña.

La fase previa de nuestro estudio comparativo de la publicidad en radio y televisión reveló que en algunas campañas los anuncios radiofónicos y los televisivos parecían iguales, con copys y bandas sonoras muy similares, como si entre piezas se hubiera llevado a cabo una traducción, mientras que en otras el concepto creativo se adaptaba de un medio a otro para transmitir historias o ejemplos distintos de los se desprendía un mismo mensaje o idea de fondo. Sin embargo, los grados de similitud y de diferenciación eran muy variados, por lo que se optó por ampliar la categorización traducción-adaptación, generando tres sub categorías para cada una de ellas.

\subsection{Tipos de traducción ${ }^{8}$}

\section{Traducción mecánica}

Es aquella en la que los audios de la cuña y del spot son iguales, por lo que se entiende que, a partir de la producción en uno de los medios, se ha elaborado la 
punto de vista auditivo (considerando cómo han de oírse las cosas para que todo lo que suena se entienda sin ningún apoyo visual), la cuña puede perder eficacia e, incluso, sentido. En cambio, cuando sí es así, la creatividad puede funcionar en ambos medios, al entenderse el audio y complementarlo, en televisión, con una plasmación concreta de la imagen.

Formarían parte de esta categoría los radio replay (Edell i Keller, 1989), aunque sólo se podrá afirmar con seguridad que la cuña es el audio del spot pasado por la radio en aquellos casos en los que se detecten errores de codificación que causen ruidos en la cuña, surgidos cuando, al faltar la imagen, las fuentes sonoras no son suficientemente identificables, cosa que genera cierta dependencia de la pieza radiofónica respecto a la televisiva.

Es el caso de la campaña de Iberdrola lanzada en febrero de 2010, en la que los audios de los anuncios son iguales, aunque en el radiofónico se eliminaron los primeros segundos que suenan en la versión televisiva. La cuña conserva, integrados en la música de fondo, el sonido de varios objetos que se veían en el spot, pero que en radio no se entienden, porque sus fuentes no se identifican y ninguno de los otros elementos sonoros -ni la música, ni el copy- ayuda a sugerir sus imágenes. Además, a pesar de usar los mismos recursos acústicos, la versión radiofónica tampoco recrea el ambiente bucólico del anuncio de televisión, creado mediante un lenguaje audiovisual rico basado en las imágenes y reforzado por la música y los efectos.

\section{Traducción esencial}

Se da cuando el mensaje es codificado con un copy muy parecido en cada uno de los lenguajes específicos de los diferentes medios. Por ello, los anuncios pueden ser percibidos como iguales en su componente audio, aunque en realidad incluyen leves diferencias. Éstas facilitan la comprensión del mensaje y pueden concretarse en la reorganización de las frases del discurso, la transcodificación de elementos de una modalidad comunicativa del mensaje a la otra -palabras locutadas en la cuña que se transforman en palabra escrita o en imágenes en el spot, o viceversa-, su duplicación, la introducción o la eliminación de deícticos, o la variación del número de personajes, acciones y espacios secundarios o ilustrativos, entre otros.

A pesar de estos ajustes, las imágenes generadas sonoramente en la cuña y las del spot no coinciden, por lo que algunos significados connotados pueden perderse de una pieza a la otra, aunque la información básica sea la misma. Se puede ver un ejemplo de ello en la campaña de Gas Natural Fenosa sobre el Plan ServiGas: aunque el copy es prácticamente igual (con la diferencia de que en la cuña Gemma Mengual 
Sin embargo, esto no se traslada a la radio. En la cuña, el técnico desaparece y no suena ningún efecto sonoro que haga pensar que el entorno es una casa; no se crea ningún paisaje sonoro y se entiende que la famosa habla desde un estudio, perdiendo fuerza, así, su argumento.

Lo mismo sucede con las piezas de la campaña de Puleva Omega 39 , del año 2010. En ellas el copy es prácticamente idéntico: un texto informativo que explica que muchos consumidores agradecen a la marca sus propiedades beneficiosas para la salud. En el spot esta gratitud se hace patente mediante la imagen de diversos personajes, en diferentes momentos de su vida cotidiana y en ambientes muy distintos, que miran a cámara sonriendo y se dan dos golpecitos sobre el corazón en señal de agradecimiento. En la cuña el sonido de los golpes desaparece, ya que, sin haber visto la versión televisiva, no se entenderían, pero no se substituye por ningún otro elemento, de modo que todos esos testimonios silenciosos se pierden.

\section{Traducción integral}

Se diferencia de la anterior en que las imágenes generadas por ambos anuncios son parecidas -nunca podrán ser exactamente iguales porque el paso de un lenguaje formado por una componente doble (visual y sonora) a una de simple (sonora), casi siempre supondrá una pérdida mínima de información, y el proceso contrario una ganancia- y, en consecuencia, no desaparecen en tan gran medida los valores connotados.

Fénix Directo utiliza esta fórmula en 2010, en sus anuncios sobre seguros de coche y moto. La cuña es informativa y usa un lenguaje simple y directo; el spot, con un copy prácticamente igual, se sirve de la imagen para reforzar el discurso verbal mediante la repetición de la información por escrito (aparecen sobreimpresos el nombre de la marca, los tipos de seguros y sus tarifas, el número de teléfono, etc.) y la redundancia de las imágenes (se ve un coche cuando se habla del seguro para automóviles; una moto, cuando se menciona el de motocicletas...). Además, para evitar la monotonía, aprovecha el movimiento de las imágenes y del texto para generar cierto dinamismo, e introduce un locutor de más para amenizar el discurso oral.

La campaña de la DGT y la Cruz Roja, $A a$, del mismo año, también cabe en esta categoría. Para una mayor comprensión del discurso, los párrafos del copy se ordenan de forma diferente en radio que en televisión y hay elementos que pasan de la modalidad sonora a la visual (el ejemplo de "Aa María" se menciona en la cuña y se ve en la pantalla de un móvil en el spot). En ambos casos la escena (vista o imaginada) es similar y se percibe desde la distancia: las imágenes del spot muestran 
cercanos al accidentado, ni se oyen efectos en primer plano; en la cuña, suenan de fondo sirenas, puertas de vehículos que se cierran, avisos por radio y murmullo de gente que no llegan a entenderse.

\subsection{Tipos de adaptación}

\section{Adaptación conceptual o de unidad estética}

Se da cuando los anuncios de radio y televisión no se perciben como iguales, ya que tienen copys diferentes (aunque la parte corporativa pueda ser más o menos similar) en los que se plantean situaciones distintas, pero con un mismo tono y estilo creativos, manteniendo así la unidad estética entre ellos. Este cambio de planteamiento se produce por una necesidad de adaptación a las características del medio: suele usarse, por ejemplo, cuando el spot se basa en efectos visuales o cuando desarrolla una historia muy elaborada, con una duración larga y un orden más o menos complejo.

En esos casos, como las cuñas no disponen de información visual directa y, en consecuencia, deben construir los personajes, los espacios y las acciones sonoramente -por lo que se necesita tiempo para que suenen, un tiempo del que normalmente no se dispone-, se adaptan buscando un planteamiento similar, pero más sencillo y accesible acústicamente.

Un ejemplo serían las piezas, analizadas en la fase previa del estudio, de la campaña Cada número una persona, de la ONCE, en la que la cuña y el spot comparten personajes principales, pero presentan fragmentos distintos del encuentro entre ellos. Estos segmentos, que forman parte de un reportaje más amplio que explica el día a día de una persona ciega, mantienen una unidad estética $y$, por ello, se perciben como parte de un todo en el momento de la recepción-escucha, aunque expliquen capítulos distintos de una historia en común.

En la campaña de Vodafone sobre el Plan Conecta Voz e Internet para empresas, también de 2010, la unidad estética se mantiene gracias a una misma música de fondo en las dramatizaciones de ambos anuncios, a cierto tono cómico (favorecido por el fragmento musical elegido, aunque mucho más acusado en el spot por el refuerzo de las imágenes) y al uso del motivo del café como centro del conflicto en las dos historias, que podría llegar a pensarse que están vinculadas (es decir, que uno de los oficinistas del spot es el que ha ido a robar el café a la oficina de enfrente en la cuña).

A adaptación, en este caso, nace de la necesidad de simplificar la historia en radio y pasa por la reducción del número de personajes, acciones y espacios representados 
conectar con otra dimensión a través de un portal al estilo stargate ${ }^{11}$.

Ante la dificultad de representar sonoramente dicho artefacto de manera comprensible para toda la audiencia (no sólo para los fans de la serie), en la cuña radiofónica se optó por sustituir la puerta estelar por una médium que comunicaba con el más allá. De esta manera se mantenía el planteamiento de ambas piezas como una dramatización o ficción con toques fantásticos y con un tono humorístico, pero la historia se hacía perfectamente comprensible en cada uno de sus medios correspondientes.

\section{Adaptación bitonal}

A diferencia de la anterior, pero por las mismas causas posibles, en esta categoría el tono y/o el estilo creativo varían de un medio al otro, por lo que las piezas sólo se identifican como pertenecientes a la misma campaña por la música, por la locución corporativa o por el claim $^{12}$.

Un ejemplo muy claro es la campaña de Gas Natural Fenosa La felicidad se genera en casa. El spot explica, rebobinadamente, un día en la vida de una pareja feliz, que empieza con buen pie gracias al servicio que le da el anunciante. Como la historia narrada es larga (55”) y compleja, no sólo por su estructura temporal y el efecto de rebobinado, sino también por la gran cantidad de personajes, espacios y acciones que se representan, el concepto creativo se adapta de manera distinta al medio radiofónico (cuya pieza dura 25"), manteniendo únicamente la música y la parte corporativa (único momento del spot en el que hay un texto oral) como elementos de unión entre ambas piezas de la campaña. Sin embargo, mientras que el anuncio televisivo tiene un tono más bien cálido, la cuña -que dramatiza la comunicación pública de un descubrimiento científico (dónde se genera la felicidad)-, intenta generar mediante el copy un cierto efecto humorístico.

La adaptación bitonal se consigue también en los anuncios de 2010 sobre las estaciones de servicio de Repsol. El televisivo dramatiza una situación concreta que demuestra el lema de la campaña ("encuéntralo todo"), mientras que el radiofónico tiene un estilo informativo. La música final corporativa y la referencia directa del copy de la cuña al spot ("como en el anuncio de Repsol"), son los únicos elementos que identifican ambas piezas como de la misma campaña.

11 Stargate: puerta a las estrellas es un film de Roland Emmerich, estrenado en 1994, del cual posteriormente se realizaron 3 series de televisión. El icono de la saga es la puerta estelar o stargate, un gran círculo que al activarse (con un efecto especial que animaba el centro del aro con una textura 
Audi también utiliza esta fórmula en 2010 para anunciar su modelo A1. El anuncio de televisión es conceptual y absolutamente visual: en 33 segundos se contabilizan 50 planos montados sobre una base musical trepidante en la que la perspectiva hace que los objetos formen una " $\mathrm{A}$ ". El resultado es una sensación de obsesión por el coche, que es deseado y está en todas partes del entorno urbano mostrado. Además, los efectos sonoros, en una intensidad hiperrealista, y la ausencia de voz consiguen crear un anuncio difícil, por no decir imposible, de traducir a la radio.

En las versiones radiofónicas ${ }^{13}$ para la comunidad autónoma de Cataluña, menos aceleradas (excepto en la parte corporativa), la seducción es el elemento clave y los efectos sonoros (menores y en segundo plano) remiten a un entorno urbano. La palabra, eje de las piezas sonoras, sirve para dramatizar una historia que humaniza al coche, un seductor que atrae las miradas de hombres y mujeres.

\section{Adaptación multiconceptual}

Se produce cuando a partir del anuncio para uno de los medios se crean varias piezas para el otro, cada una de ellas centrada en un único aspecto del producto o servicio, de entre todos aquellos incluidos en el primero, con el fin de evitar un exceso de información. Cuando de un producto, servicio o promoción se quieren destacar varios aspectos suele ser más efectivo hacerlo mediante diversas cuñas (una sobre cada cualidad), antes que abigarrar un solo mensaje que los incluya todos. Este tipo de adaptación se puede llevar a cabo manteniendo en mayor o menor grado la unidad estética entre piezas de ambos medios.

La campaña de 2010 sobre Bonos del Estado, del Tesoro Público, sirve para ejemplificar esta categoría. En el spot se resaltan la rentabilidad, la comodidad y la tranquilidad como principales beneficios que reporta el producto. La cuña, en cambio, se centra únicamente en el concepto de comodidad y se aproxima a él en un tono diferente al del spot, más irónico. Sin embargo, la campaña mantiene puntos en común entre ambas piezas, como la música de fondo y el eslogan.

Ikea también opta por esta fórmula para anunciar su catálogo 2011, al mostrar varios productos con sus nuevos precios en el spot, y centrarse sólo en uno en la cuña. El anuncio televisivo, de estilo informativo y más directo que la pieza sonora, muestra varios muebles con sus precios antiguos y nuevos sobre fondos de colores llamativos, mientras suena una música y la voz en off de una locutora que anuncia la reducción de los precios de los principales productos. 
En el radiofónico, en cambio, además de la locutora corporativa que anuncia ambos precios del sillón, al principio de la cuña se recrea un espacio distinto (con ruido de gente de fondo) en el que aparece un personaje que introduce un comentario, el cual intenta reforzar la idea del cambio por antítesis. Dice: hay cosas que se mantienen de año en año, como "las ganas de ver tres capítulos seguidos de una misma serie", y otras que no, como los precios de la marca sueca.

\section{CONCLUSIÓN}

La categorización descrita en este artículo pone de relieve la variedad de opciones a disposición de las agencias publicitarias a la hora de crear piezas radiofónicas y televisivas para una campaña. La elección de fórmulas de traducción o de adaptación dependerá de factores muy diversos, entre ellos, la naturaleza del concepto creativo, el presupuesto dedicado a cada medio (que, muy a menudo, va ligado al interés que el anunciante tiene por ellos) y el conocimiento de los lenguajes radiofónico y televisivo por parte de los creativos.

A pesar de que las categorías planteadas se establecen en función de la similitud o fidelidad entre las piezas -y no según una escala de calidad-, la destreza en el manejo de la voz o la palabra, la música, los efectos sonoros y el silencio para la creación de imágenes sonoras determinará en gran medida el tipo de fórmula elegida, sobre todo en los casos de traducción.

Las diferencias de tiempo dedicado a las piezas televisivas (que pueden llegar hasta un minuto de duración) y a las radiofónicas (que no suelen superar los 30 segundos), serán también una de las principales causas de optar por la adaptación, así como la complejidad visual (presencia de los colores, uso de efectos especiales, etc.) y la elaboración de las historias televisivas, que, como se ha visto en los ejemplos de Gas Natural Fenosa y Vodafone, son difíciles de plasmar sonoramente con un tiempo tan limitado.

No es objeto de este texto evaluar ni juzgar qué tipo de estrategia es mejor, la apuesta por la fidelidad o por la adaptación. Aunque el uso de fórmulas de traducción sea interpretado por algunos como una manifestación de la dependencia creativa de la radio respecto a la televisión, lo cierto es que la plasmación de la idea de forma distinta en ambos medios no garantiza una explotación óptima de las posibilidades del lenguaje.

La fase previa del estudio comparativo de la publicidad en radio y televisión concluyó que, aunque las campañas observadas -comentadas en los epígrafes anteriorescontaban con piezas radiofónicas que funcionan, en mayor o menor grado, con 
Será tarea de las siguientes etapas del estudio profundizar en aspectos más concretos de la explotación de los lenguajes radiofónico y televisivo, y establecer cuáles serán los índices que permitirán evaluar concretamente la dependencia o subordinación de la radio respecto a la televisión en cada categoría.

\section{REFERENCIAS}

Balsebre Torroja, A. et. Al. (2006). Los mitos de la publicidad radiofónica. Madrid: Cátedra.

Chaume, F. (2003). Doblatge i subtitulació per a TV. Vic: Eumo Editorial.

Fernández Díaz, F. \& Martínez Abadía, J. (1999). Manual básico de lenguaje y narrativa audiovisual. Barcelona: Paidós.

García González, A. (1998). La producción publicitaria en la radio. Vigo: Servicio de Publicacións da Univerisade de Vigo.

Hernández Martínez, C. (1999). Manual de creatividad publicitaria. Madrid: Síntesis.

Huertas Bailén, A. \& Perona Páez, J. J. (1999). Redacción y locución en medios audiovisuales: la radio. Barcelona: Bosch.

Millerson, Gerald (2001): Técnicas de realización y producción en TV. Madrid: IORTV.

Shulberg, B. (1992). Publicidad radiofónica. El manual autorizado. México:

McGraw-Hill.

Rifkin, B. (1994). Semiotics of narration in film and prose fiction. Case studies of "Scarecrow" and "My friend Ivan Lapshin. Nueva York: Peter Lang.

Barbeito Veloso, Ma L. \& Vázquez Gestal, M. (1999). La radio, un medio publicitario infravalorado. La publicidad en la radio. VI xornadas de comunicación social.

BernadaS Suñé, D. \& Arcos Foix, N. (2011). Estudio comparativo de la publicidad en radio y televisión. En Estudio, innovación y desarrollo de proyectos en comunicación social en el EEE. Madrid: Vision Libros.

Barbeito Veloso, Ma L. \& Fajula Payet, A. (2005). La radio publicitaria: el peso del inmovilismo. Quaderns del CAC, 22: 49-62. 
Edell, J.A. \& Keller, K.L. (1989). The information processing of coordinated media campaigns. Journal of Marketing Research, XXVI: 149-163.

Perona Páez, J. J. (2007). Formatos y estilos publicitarios en el prime-time radiofónico español: infrautilización y sequía de ideas. Zer, 23: 219-242.

Barbeito Veloso, M ${ }^{\mathrm{a}}$ L. \& Fajula Payet, A. (2009). La sono-esfera digital como nuevo entorno creativo. Trabajo presentado al I Congreso Internacional Ciudades Creativas. UCM, Madrid, 21-24 octubre de 2009. Recuperado el 15 de julio de 2011, de http://www.clonica.net/usuario/img_usuario/publiradio.net/Des_Inv/la_sonoesf era_digital_como_nuevo_entorno_creativo-2351.pdf

Rodero Antón, E. (2008). Publicidad en radio: Publicidad, sí, pero no radiofónica. Área Abierta, 20. Recuperado el 12 de julio de 2011, de http://www.ucm.es/BUCM/revistas/inf/15788393/articulos/ARAB0808230001E.P $\underline{\mathrm{DF}}$

\section{Dolors Bernadas i Suñé}

Licenciada en Ciencias de la Información (1990). Doctora por la UAB en la especialidad de Nuevas tecnologías: Comunicación Audiovisual (2001). Desde 1994 imparte clases en la UAB en Periodismo, Comunicación Audiovisual y Publicidad, centrando su actividad en el ámbito de los lenguajes radiofónico y televisivo. Como investigadora ha impulsado y desarrollado proyectos dirigidos a la mejora de la práctica y la calidad docente. También ha participado en varios grupos de investigación en proyectos financiados relacionados con la expresión emocional, el análisis instrumental, el uso de la voz y el sonido. Actualmente forma parte de Publiradio, Grup de Recerca en Publicitat i Comunicació Radiofònica.

\section{Núria Arcos Foix}

Licenciada en Comunicación Audiovisual por la UAB (2006). Actualmente es doctoranda en Comunicación Audiovisual y Publicidad, en el Departamento de Publicidad, Relaciones Públicas y Comunicación Audiovisual de la UAB. En 2009 se incorporó a Publiradio, Grup de Recerca en Publicitat i Comunicació Radiofònica, primero como becaria y más tarde como técnica especialista de apoyo a la investigación. 